Retraction

\title{
Retraction: Ling, W. et al. Evaluation of Anti-Obesity Activity, Acute Toxicity, and Subacute Toxicity of Probiotic Dark Tea. Biomolecules 2018, 8(4), 99
}

\section{Biomolecules Editorial Office}

St. Alban-Anlage 66, 4052 Basel, Switzerland; biomolecules@mdpi.com

The Biomolecules Editorial Office has been made aware that the published paper [1] was previously published in chinese in China Tea Processing by the same authors [2]. In order to preserve academic integrity, the title paper [1] will be marked as retracted. We apologize to the readership of Biomolecules for any inconvenience caused. The decision to retract has been made in cooperation with the authors of the article [1].

MDPI is a member of the Committee on Publication Ethics and takes the responsibility to enforce strict ethical policies and standards very seriously. To ensure the addition of only high quality scientific works to the field of scholarly publication, [1] is retracted and shall be marked accordingly.

\section{References}

1. Ling, W.; Li, S.; Zhang, X.; Xu, Y.; Gao, Y.; Du, Q.; Wang, G.; Fan, W.; Sun, K.; Bian, J. Evaluation of Anti-Obesity Activity, Acute Toxicity, and Subacute Toxicity of Probiotic Dark Tea. Biomolecules 2018, 8, 99. [CrossRef] [PubMed]

2. Sun, K.; Li, S.; Wang, G.; Fan, W.; Wang, L.; Bian, J. Acute and Chronic Toxicity Test of Probiotic Tea Produced by Fresh. China Tea Process. 2017, 2, 11-15.

(C) 2019 by the author. Licensee MDPI, Basel, Switzerland. This article is an open access article distributed under the terms and conditions of the Creative Commons Attribution (CC BY) license (http:/ / creativecommons.org/licenses/by/4.0/). 